[Okafor *, Vol. 4(2): March, 2020]

\title{
THERMODYNAMIC ANALYSIS OF COMPRESSOR INLET AIR PRECOOLING TECHNIQUES OF A GAS TURBINE PLANT OPERATIONAL IN NIGERIA ENERGY UTILITY SECTOR
}

\author{
V.C. Okafor ${ }^{* 1}$ \\ ${ }^{* 1}$ Department of Agricultural and Bioresources Engineering, Federal University of Technology, \\ Owerri, Nigeria
}

DOI: https://doi.org/10.29121/IJOEST.v4.i2.2020.74

\begin{abstract}
Thermodynamic analysis of inlet air pre-cooling techniques of compressor is among the methods for the enhancement of gas turbine performance. This study compared the effect of using evaporative cooling system pre-cooling method, vapour compression refrigeration precooling and vapour absorption refrigeration precooling techniques to the gas turbine Net Power Output, Thermal efficiency, Thermal Efficiency Change factor (TEC) and Power Gain Ratio (PGR) taking into recognition the prevalent weather and climatic conditions of Nigeria and as well as optimization parameters for the reference system (i.e. without precooling techniques). The results show that at air temperature of $311 \mathrm{~K}$, the reference system, evaporative precooling, vapour compression refrigeration and vapour absorption refrigeration precooling methods recorded Net power Outputs of 23.143MW, 25.39MW, 31.84MW and 34.90MW respectively. The Thermal Efficiency Change factor recorded by the precooling systems at an ambient temperature of $311 \mathrm{~K}$ is $8.68 \%, 37.4 \%$ and $51 \%$ respectively.
\end{abstract}

Keywords: Thermodynamics; Inlet air; Turbine; Efficiency; Refrigeration; Energy.

\section{INTRODUCTION}

Nigeria as a case study does not have a homogeneous climate and weather conditions. This indicates that the condition of climate in the Northern part is relatively different from Southern part. Based on this, the precooling techniques employed in the southern region of Nigeria may not be favourable in the Northern region. This study is important because it compares different precooling methods and recommends the method that will be appropriate for a particular region with regard to the particular climatic conditions. It is a well-known fact that gas turbines produce less power when the ambient temperature is hot. According to Wash and Fletcher (2004), at high inlet air temperature (i.e. $26^{\circ} \mathrm{C}$ and above), the air density is significantly reduced and consequently, the mass flow-rate of the inlet air to the compressor is reduced. Turbine inlet air precooling is defined as the precooling of the air before entering the compressor. The main purpose of turbine inlet air precooling is to increase the net power output of the gas turbine when the ambient air temperature is higher than the standard conditions. According to Al-Tori (2009), the rated capacities of all gas turbine are usually based on the standard ambient conditions of $15^{\circ} \mathrm{C}$ and $14.7 \mathrm{psi}$ at sea level. Alok et al. (2012), poses that greatest losses in output power of a gas turbine is usually during the periods when the electricity demand is greatest. A gas turbine can lose about $7 \%$ of its nominal power when the intake temperature ranges from $15^{\circ} \mathrm{C}$ to $25^{\circ} \mathrm{C}$, and when the ambient temperature is above $25^{\circ} \mathrm{C}$, the loss may reaches about $15 \%$. By cooling the air at the compressor inlet below that of the 
ambient the plant performance during high ambient temperatures will be improved. The compressor work decreases as the inlet air temperature decreases, thus increasing the overall cycle efficiency. However, a drop in the inlet air temperature increases air density which in turn increases the mass flow-rate of air entering the compressor resulting in enhanced power output. The inlet air precooling techniques investigated in this study are evaporative precooling and mechanical precooling (vapour compression and vapour absorption refrigeration precooling) techniques. In the evaporative pre-cooling method, the inlet air cools as it comes in contact with a cooling fluid, such as fog, water sprays, or a combination of both, (Wang, 2009).

\section{MATERIALS AND METHODS}

For this research, an open cycle HITACHI - MS - 7001B Gas turbine plant located in Nigeria Agip Oil Company plant yard in Obrikom, Omoku, Rives State, Nigeria was considered. Its operating data were collected from the daily turbine control log sheet for a period of ten years. The plant was divided into different control units namely compressor, turbine and precooling units.

Thermodynamic principles were used on each of the units to determine the gas turbine performance. The performance of the plant without pre-cooling technique was determined first and then its performance when each of the cooling methods (evaporative cooling, vapour compression and vapor absorption cooling) were used to pre-cooled the inlet air before entering the plant.

\subsection{Description of the Plant}

Fig. 3.1 shows the diagram of a single shaft gas turbine (HITACHI -MS - 7001B) cycle, the type considered in this work. The compressor compressed the ambient air thus raising its temperature before it enters the combustion chamber. Fuel is sprayed into the high temperature air in the combustion chamber. Combustion of fuel takes place and the resulting hot gas expands resulting in mechanical work which drives the turbine shaft.

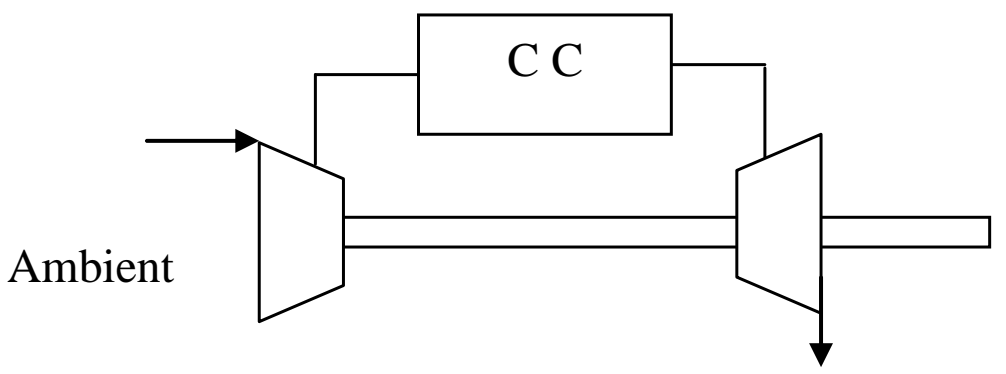

Figure 3.1: Diagram of a gas turbine cycle.

\subsection{The Gas Turbine Unit}

Based on Fig. 3.1 above, the compressor inlet air temperature is the ambient air temperature when precooling effect is neglected. Applying the polytropic relations for ideal gas and knowing the isentropic efficiency of the compressor, the compressor inlet temperature $\left(\mathrm{T}_{1}\right)$ is given by: 
This section should provide enough detail to allow full replication of the study by suitably skilled investigators. Protocols for new methods should be included, but well-established protocols may simply be referenced.

$$
\frac{T_{2 s}}{T_{1}}=\left(\frac{P_{2}}{P_{1}}\right)^{r-1 / r}
$$

\section{Where:}

$\mathrm{T}_{2 \mathrm{~s}}$ is the isentropic temperature at the compressor outlet $(\mathrm{K}) ; \frac{\mathrm{P}_{2}}{\mathrm{P}_{1}}$ represents the ratio of the pressure; $\mathrm{r}$ is the specific heat ratio, and $\mathrm{T}_{1}$ is the compressor inlet temperature $(\mathrm{K})$.

The power to drive the compressor can be calculated by

$$
\dot{W}_{c}=\dot{m}_{a} C_{p a}\left(T_{2}-T_{1}\right)
$$

Where:

$m_{a}$ is mass flow-rate of air $(\mathrm{kg} / \mathrm{s}), C_{p a}$ is the specific heat capacity of dry air at constant pressure $(\mathrm{KJ} / \mathrm{Kg} \mathrm{K})$ and $T_{2}$ is the compressor exits temperature $(\mathrm{K})$.

The heat generated during combustion by is determined as:

$$
Q_{\text {in }}=C_{p a}\left(T_{3}-T_{2}\right)
$$

Where: $T_{2}$ is the inlet temperature in the combustion chamber $(K)$, and $T_{3}$ is the outlet temperature in the combustion chamber $(\mathrm{K})$,

The turbine discharge temperature $\left(T_{4}\right)$ is defined as (Rahem et al., 2006):

$$
T_{4}=T_{3}-\eta_{T} T_{4 s}\left[1{\frac{1}{\left(\frac{P_{3}}{P_{4}}\right)^{\frac{r-1}{r}}}}^{r}\right]
$$

\section{Where:}

$\eta_{T}$ is isentropic efficiency of the turbine (\%),

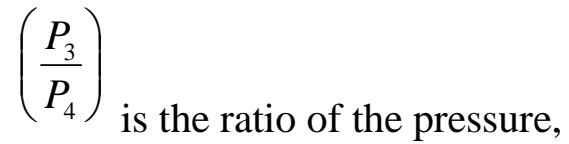

$\mathrm{T}_{4 \mathrm{~s}}$ is the turbine discharge isentropic temperature $(\mathrm{K})$.

The power generated by the turbine is defined as: 
$\dot{W_{T}}=\dot{m}_{T} C_{p g}\left(T_{3}-T_{4 s}\right)$

\section{Where:}

$m_{T}$ is the mass flow-rate of the charge and it is given as:

$m_{T}=\dot{m}_{a}+\dot{m}_{f}$

\section{Where:}

$m_{a}$ and $m_{f}$ are mass flow-rate of air and fuel respectively,

$C_{p g}$ is the specific heat capacity of the gas at constant pressure $(\mathrm{KJ} / \mathrm{Kg} \mathrm{K})$.

The Net Power generated by the gas turbine plant is given as:

$\dot{W_{n e t}}=\dot{W}_{T}-\dot{W_{C}}$

The specific Fuel Consumption (SFC) is given as:

$\mathrm{SFC}=\frac{3600 m_{f}}{W_{n e t}}$

The thermal efficiency of the gas turbine plant is given as:

$\eta_{t h}=\frac{3600}{S F C X N C V}$

Where:

$\mathrm{NCV}$ is the Net fuel Calorific Value $(\mathrm{KJ} / \mathrm{Kg})$.

\subsection{Description of the Gas Turbine Coupled with Inlet Air Precooling Techniques}

Fig. 3.2. Shows a schematic diagram of the gas turbine with a precooling system. It comprises of a standard gas turbine plant and an inlet air precooler. 


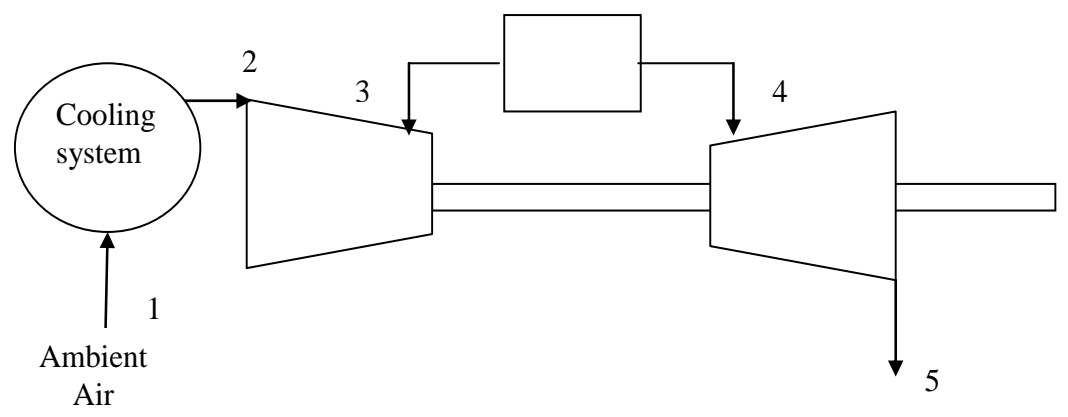

Figure 3.2: Schematic diagram of a gas turbine cycle with precooling techniques.

\subsection{Evaporative Precooling Techniques}

In evaporative method of pre-cooling, the sensible heat energy of air is utilized to evaporate water and in the process the air temperature drops below the ambient. According to Meher-Homji (2000), in evaporative pre-cooling of turbine inlet air, droplets of water, 5-20 microns in diameter, are sprayed into the air inlet ducts at $1000-3000$ psia. As the droplets evaporate, the air is cooled to the wet bulb temperature. Air filter are incorporated to prevent dust from entering the pre-cooling equipment and the compressor as shown in Figs. 3.3 (a) and (b)

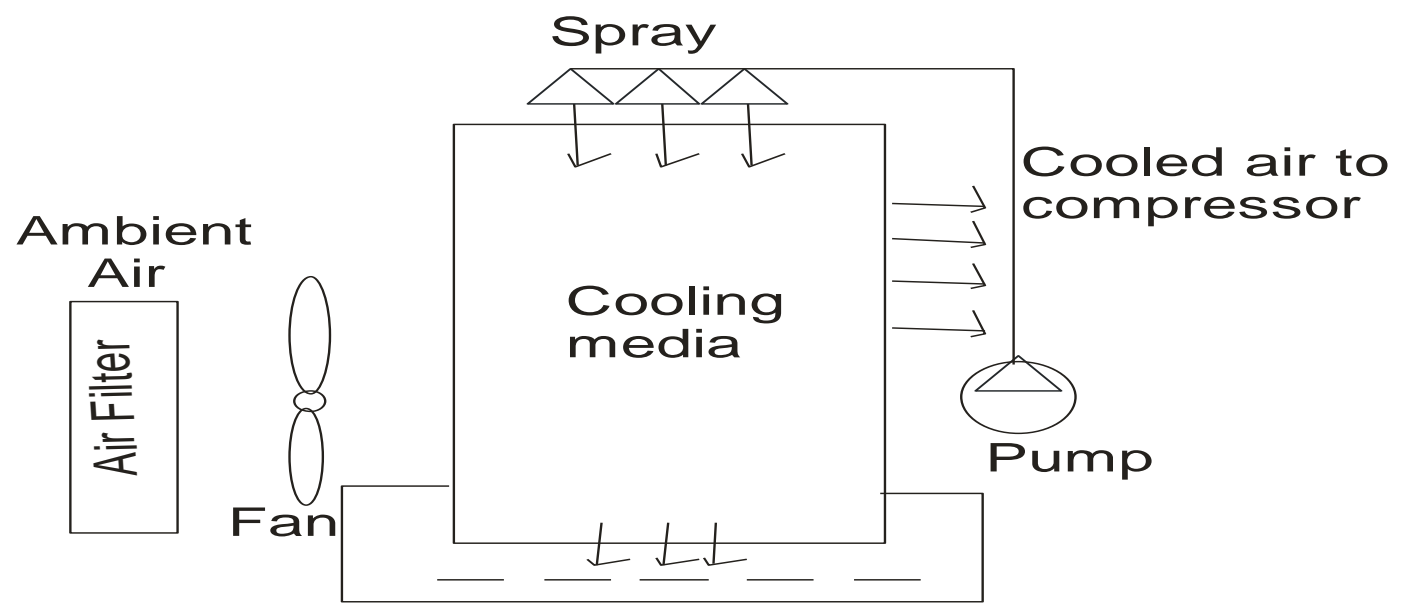

Figure 3.3 (a): Typical Architecture of the evaporative precooling system.

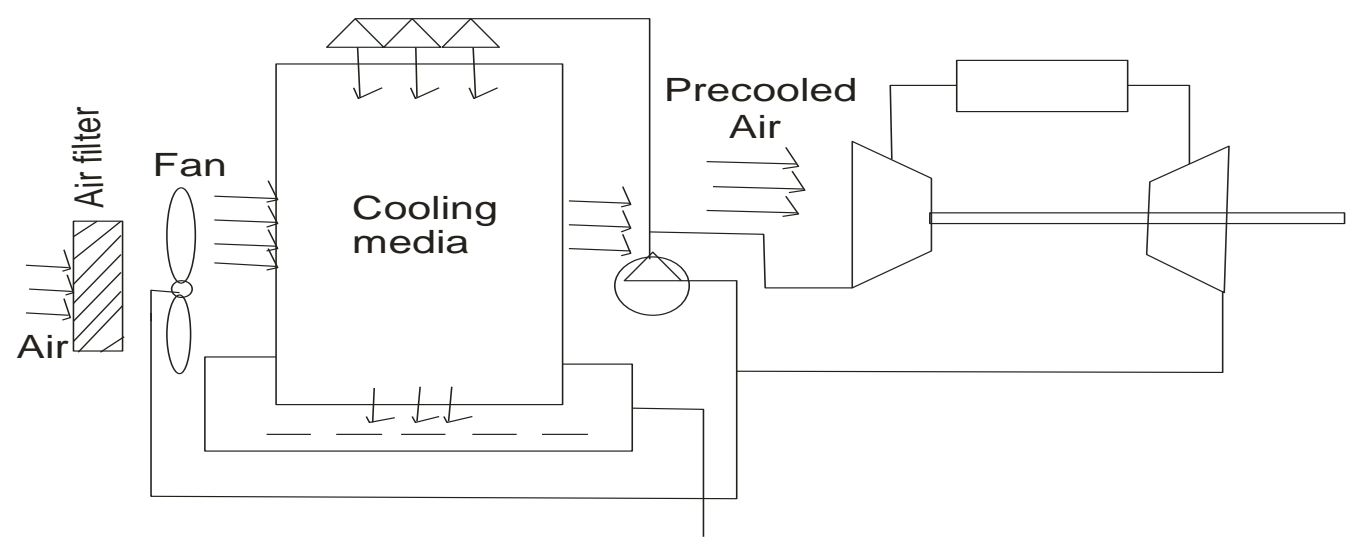

Figure 3.3 (b): Schematic diagram of an evaporative precooling system integrated to a gas turbine plant. 
The inlet air temperature after precooling is calculated by: (Shanbghazani et al., 2008)

$$
T_{1}=T_{b 2}-\left(T_{b 2}-T_{w 2}\right) \varepsilon
$$

\section{Where:}

$T_{b 2}$ is the dry-bulb temperature $(\mathrm{K})$

$T_{w 2}$ is the wet-bulb temperature (K),

$\varepsilon$ is the evaporative precooling effectiveness (\%)

\subsection{Vapour Compression Precooling Techniques}

Vapour compression refrigeration inlet air precooling system utilizes vapour compression refrigeration equipment (compressor). Its operation/maintenance cost are lower than that of vapour absorption pre-cooling system but the high capital costs and power requirements is approximately $30 \%$ of the power gain. In this cycle the refrigerant, evaporates and condensates at suitable pressure for practical equipment design. The refrigerant used for the vapour compression refrigeration analysis in this research is ammonia $\left(\mathrm{NH}_{3}\right), \mathrm{R} 22$.

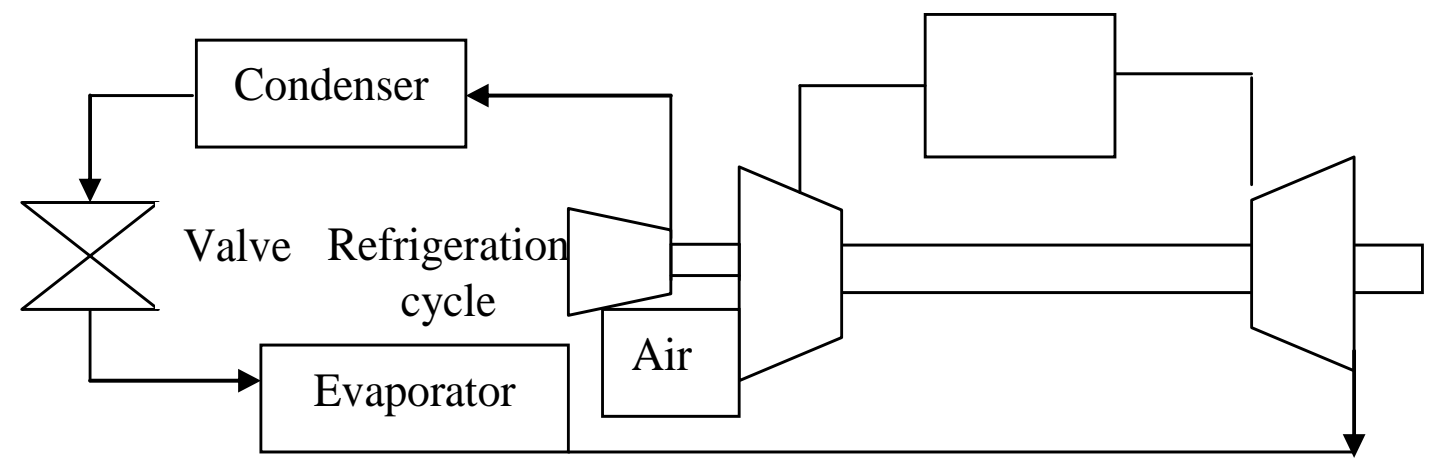

Figure 3.4: Schematic diagram of a gas turbine plant integrated with vapour compression system.

The Net Power Output for the gas turbine integrated with vapour compression system is given as:

$W_{n e t}=\dot{W_{T}}-W_{c}-\dot{W_{m c}}$

Where:

$\dot{W}_{T}, \dot{W}_{C}$ and $\dot{W}_{m c}$ are the power generated by the turbine, power consumed by the compressor and power consumed by the mechanical chiller (i.e. refrigeration cycle compressor) respectively. Power consumed by the mechanical chiller is given as:

$W_{m c}=\frac{Q_{C L}}{C O P}$ 


\section{Where:}

$\mathrm{COP}$ is the coefficient of performance of the mechanical chiller and it is equal to 32.2 for the plant studied.

$Q_{C L}$ is the cooling load of the mechanical chiller and it is given as:

$\dot{Q_{C L}}=\dot{m}_{a}\left(h_{2}-h_{3}\right)$

Where: $h_{2}$ and $h_{3}$ is the enthalpy at the mechanical chiller inlet and outlet respectively.

\subsection{Vapour Absorption Precooling Techniques}

This system consists of a pump, an absorber, a pressure reducing valve and a generator. Other components are condenser, receiver, expansion valve and evaporator. The refrigerant leaves the evaporator and enters a low temperature absorbing medium. During this process heat is given off and the absorbent solution is pumped at higher pressure. As a result of the reduced solubility of the refrigerant - absorbent solution at high temperature and pressure, refrigerant vapour is separated from the solution. The vapour passes to the condenser and the weakened refrigerant absorbent solution is throttled back to the absorber. In this study, the refrigerant is ammonia while the absorbent is water.

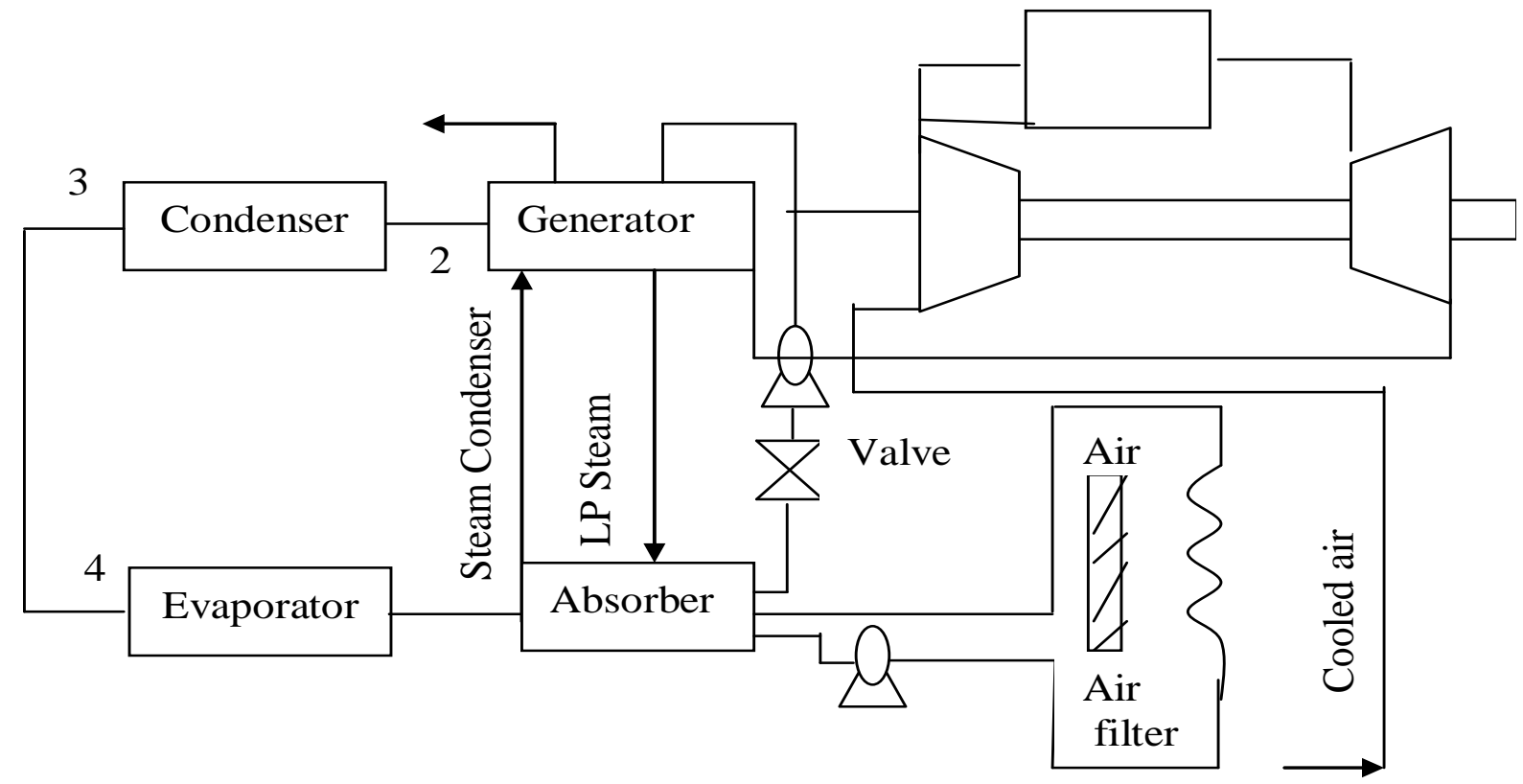

Figure 3.5: Schematic diagram of a gas turbine plant integrated with a vapour absorption refrigeration system.

Assuming that the power required to drive the liquid solution pump is negligible; the net power generated by the gas turbine plant is given as (Rahem et al., 2006):

$W_{n e t}=\dot{W}_{T}-\dot{W}_{C}-\dot{Q}_{G}$ 


\section{Where:}

$\mathrm{Q}_{\mathrm{G}}$ is the power required to drive the generator.

Applying an energy balance equation to the vapour absorption cycle in Figure 3, and neglecting pump work, we have

$\dot{Q}_{G}+\dot{Q}_{\varepsilon}+\dot{Q}_{c}+\dot{Q}_{A}=0$

Where:

$Q_{\varepsilon}, \dot{Q}_{c}$ and $\dot{Q}_{A}$ are heat supplied in the evaporator, condenser and absorber respectively and they are given as:

$\dot{Q_{\varepsilon}}=\dot{m}_{r}\left(h_{4}-h_{1}\right)$

$\dot{Q}_{c}=\dot{m}_{r}\left(h_{2}-h_{3}\right)$

$\dot{Q}_{A}=\dot{m}_{r}\left(h_{1}-h_{2}\right)$

Where:

$h_{1}, h_{2}, h_{3}$ and $h_{4}$ are enthalpies at evaporator outlet, condenser outlet, condenser inlet, condenser outlet and evaporator inlet respectively.

Substituting equations (16), (17) and (18) into equation (14), we have

$\dot{W}_{n e t}=\dot{W}_{T}-\dot{W}_{C}-\dot{m}_{r}\left(h_{4}-h_{3}\right)$

\section{Where:}

$m_{r}$ is the mass flow-rate of the refrigerant - absorbent solution given as $0.2876 \mathrm{Kg} / \mathrm{s}$.

\subsection{Evaluation Criteria of Gas Turbine Precooling System}

In order to evaluate the feasibility of a precooling system coupled to a Gas turbine plant, it is important to examine the performance of the plant with and without any precooling techniques. In order to study the performance of a gas turbine fitted with a precooling method the power gain ratio (PGR) and the thermal efficiency change (TEC) as proposed by Rahem et al. (2006) and Achazmy et al. (2006) respectively is given as:

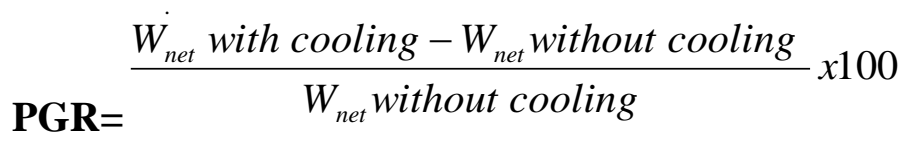

$\mathbf{T E C}=\frac{\eta_{\text {th }} \text { with cooling }-\eta_{\text {th }} \text { without cooling }}{\eta_{\text {th }} \text { without cooling }} \times 100$

http://www.ijoest.com @International Journal of Engineering Science Technologies 


\section{RESULTS AND DISCUSSIONS}

The performance of the Gas turbine plant integrated with evaporative precooling system, vapour compression precooling system and vapour absorption precooling system are investigated. Fig. 4.1 describes the effect of ambient temperature to the gas turbine Net Power output (N.P.O). At an ambient temperature of $303 \mathrm{~K}$, the gas turbine recorded a Net Power Output of $38 \mathrm{MW}, 36 \mathrm{MW}$, $25 \mathrm{MW}$ and $22 \mathrm{MW}$ for vapour absorption precooling, vapour compression precooling, evaporative precooling and when no precooling technique is involved respectively. Furthermore, at an ambient temperature of $311 \mathrm{~K}$, the Net Power Output for the reference system (i.e. no precooling system), evaporative precooling, vapour compression precooling and vapour absorption precooling are 22MW, 26MW, 31MW and 36MW respectively.

Table 4.1: Net power output obtained at different ambient temperatures for the reference system (without precooling) and the precooled systems.

\begin{tabular}{|c|c|c|c|c|}
\hline \multirow{2}{*}{$\begin{array}{c}\text { Ambient } \\
\text { temperature (K) }\end{array}$} & \multicolumn{4}{|c|}{ Net Power Output } \\
\cline { 2 - 5 } & $\begin{array}{c}\text { Reference } \\
\text { plant }\end{array}$ & $\begin{array}{c}\text { Evaporative } \\
\text { precooling }\end{array}$ & $\begin{array}{c}\text { Vapour } \\
\text { compression }\end{array}$ & $\begin{array}{c}\text { Vapour } \\
\text { absorption }\end{array}$ \\
\hline 301 & 24.79 & 26.07 & 33.17 & 36.21 \\
\hline 303 & 24.46 & 25.86 & 32.89 & 35.97 \\
\hline 305 & 24.14 & 25.80 & 32.56 & 35.75 \\
\hline 307 & 23.82 & 25.67 & 32.36 & 35.47 \\
\hline 309 & 23.50 & 25.50 & 32.11 & 35.25 \\
\hline 311 & 23.14 & 25.39 & 31.84 & 34.90 \\
\hline
\end{tabular}

Table 4.2: Power gain ratio obtained at different ambient temperatures for the precooling systems.

\begin{tabular}{|c|c|c|c|}
\hline \multirow{2}{*}{$\begin{array}{c}\text { Ambient temperature } \\
(\text { K) }\end{array}$} & \multicolumn{3}{|c|}{ Power Gain Ratio (\%) } \\
\cline { 2 - 4 } & $\begin{array}{c}\text { Evaporative } \\
\text { precooling }\end{array}$ & $\begin{array}{c}\text { Vapour } \\
\text { compression }\end{array}$ & $\begin{array}{c}\text { Vapour } \\
\text { absorption }\end{array}$ \\
\hline 301 & 5.24 & 33.80 & 46.20 \\
\hline 303 & 5.75 & 34.50 & 47.70 \\
\hline 305 & 6.92 & 32.61 & 48.10 \\
\hline 307 & 7.73 & 32.80 & 48.90 \\
\hline 309 & 8.53 & 36.60 & 50.00 \\
\hline 311 & 9.70 & 37.60 & 51.00 \\
\hline
\end{tabular}

Table 4.3: Thermal efficiency change factor obtained at different ambient temperatures for the precooling systems.

\begin{tabular}{|c|c|c|c|}
\hline \multirow{2}{*}{$\begin{array}{c}\text { Ambient temperature } \\
\text { (K) }\end{array}$} & \multicolumn{3}{|c|}{ Thermal Efficiency Change Factor (\%) } \\
\cline { 2 - 4 } & $\begin{array}{c}\text { Evaporative } \\
\text { precooling }\end{array}$ & $\begin{array}{c}\text { Vapour } \\
\text { compression }\end{array}$ & $\begin{array}{c}\text { Vapour } \\
\text { absorption }\end{array}$ \\
\hline 301 & 3.55 & 34.10 & 46.20 \\
\hline 303 & 6.30 & 35.10 & 47.70 \\
\hline 305 & 7.00 & 35.64 & 48.10 \\
\hline 307 & 7.73 & 35.80 & 48.90 \\
\hline 309 & 8.53 & 36.80 & 50.00 \\
\hline 311 & 8.68 & 37.40 & 51.00 \\
\hline
\end{tabular}




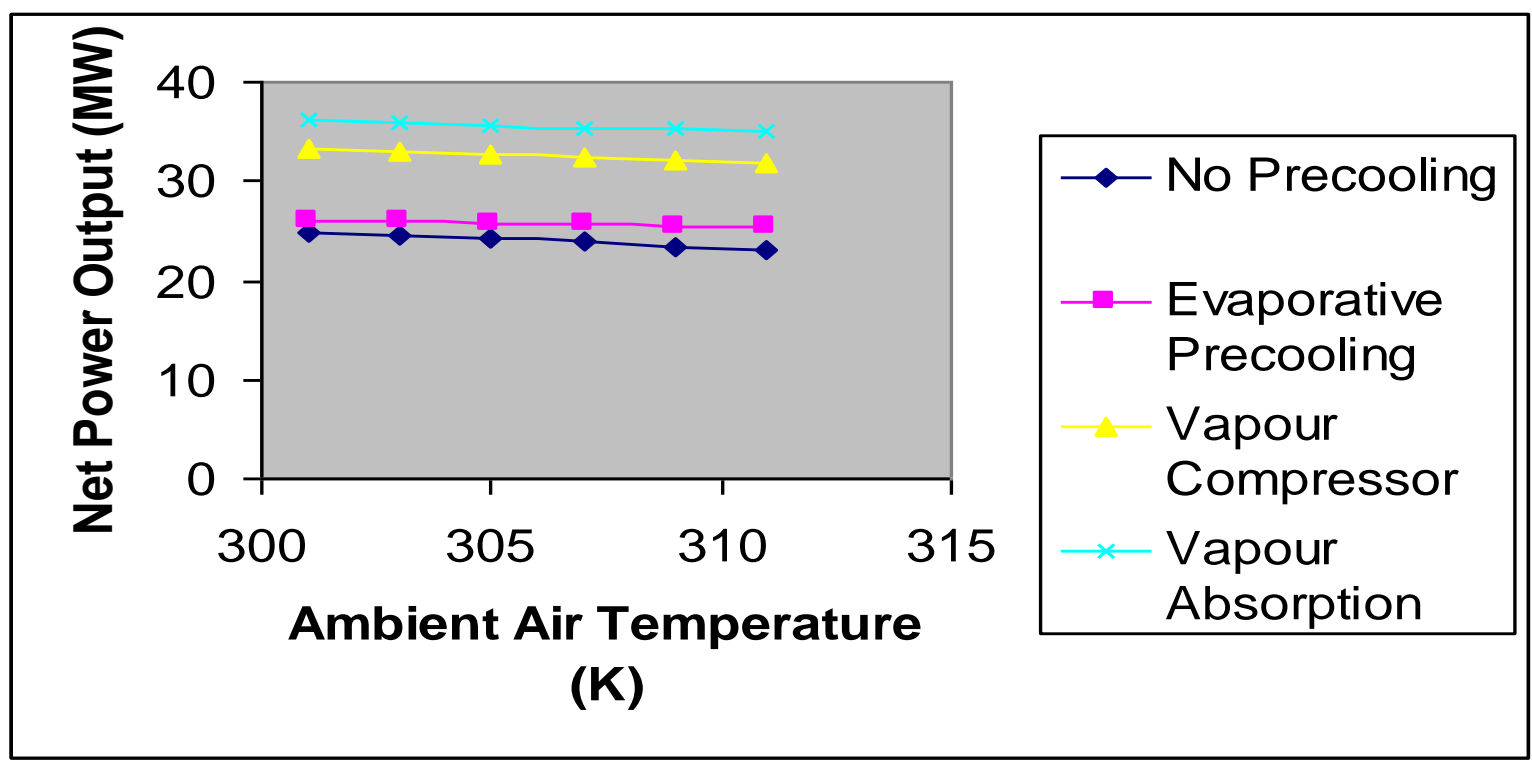

Figure 4.1: Comparison of net power output for various precooling techniques at different ambient air temperatures.

At precooled ambient temperature of $311 \mathrm{~K}$, the Power Gain Ratio of the evaporative, vapour compression and vapour absorption are $10 \%, 38 \%$ and $51 \%$ respectively (Fig. 4.2). This indicates that as the ambient temperature is reduced, the compressor consumes less work hence the net power output is increased.

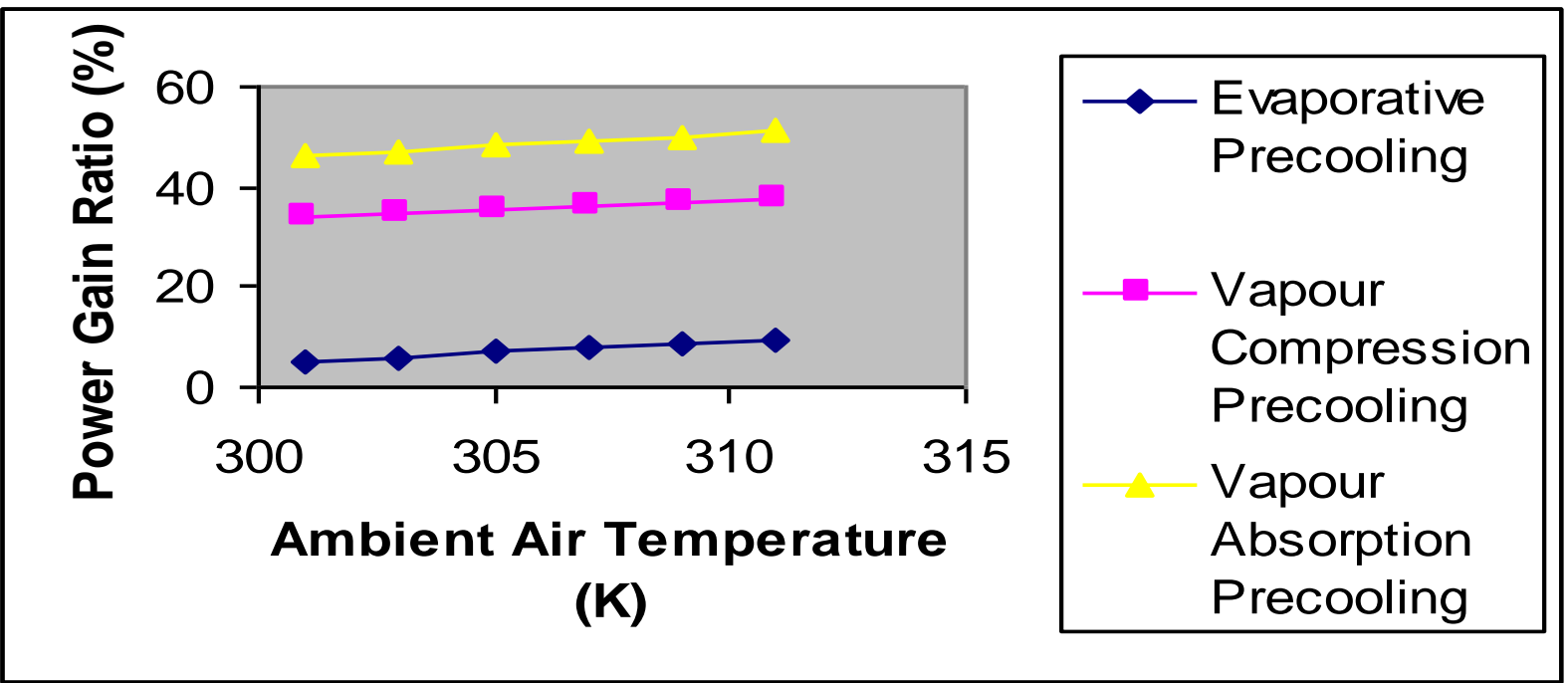

Figure 4.2: A graph of Power Gain Ratio versus Precooled Ambient Temperature

Fig. 4.3 shows the comparison of the thermal efficiency change factor for the various compressor inlet air precooling techniques. At a temperature of $311 \mathrm{~K}$, evaporative, vapour compression and vapour absorption precooling techniques measured thermal efficiency changes of $8.68 \%, 37.4 \%$ and $51 \%$ respectively. This means that the more the reduction in ambient temperature, the increase in thermal efficiency. 


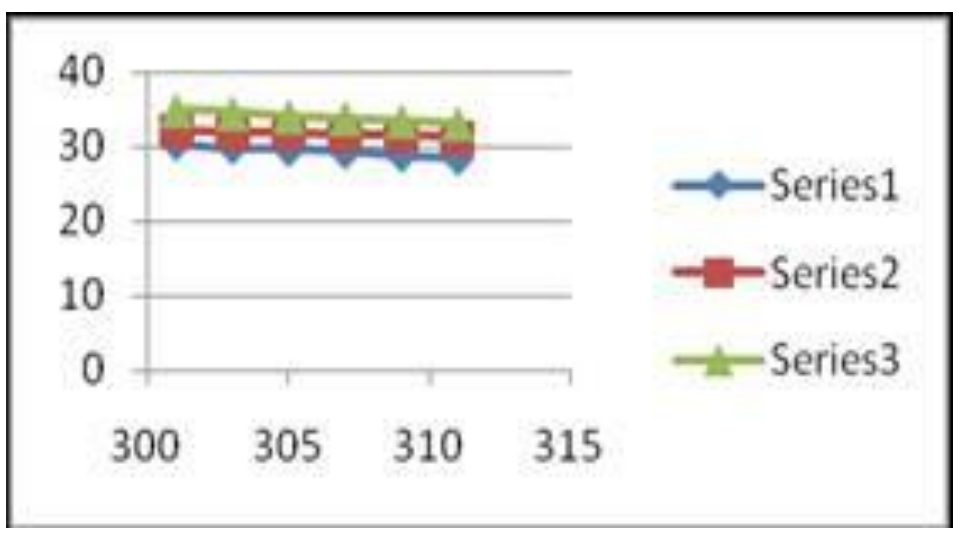

Fig. 4.4 shows that the gas turbine thermal efficiency is affected by ambient air temperature due to the change in air density and compressor work. A lower ambient air temperature will lead to a higher air density and a lower compressor. At a temperature of $311 \mathrm{~K}$, the thermal efficiency for evaporative, vapour compression and vapour absorption precooling techniques are $31.28 \%$, $32.94 \%$ and $33.09 \%$ respectively.

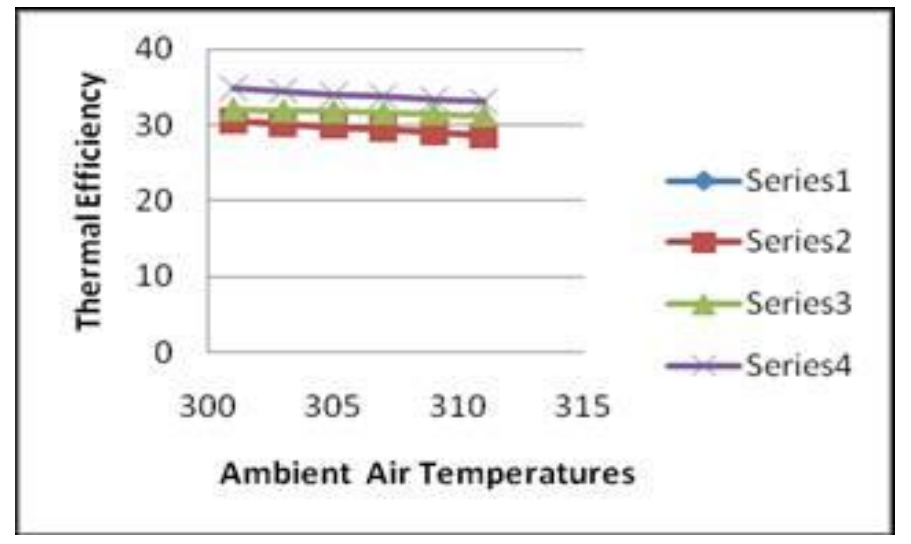

Figure 4.4: A graph of Thermal Efficiency against Ambient Air Temperature.

\section{Conclusions and Recommendations}

The performance of a gas turbine modeled with inlet air precooling techniques operational in Nigeria energy utility sector was studied and the following inferences were made:

1) The evaporative, vapour compression and vapour absorption precooling systems recorded net power outputs of $25.39 \mathrm{~W}, 31.84 \mathrm{MW}$ and $34.90 \mathrm{MW}$ respectively at an ambient temperature of $311 \mathrm{~K}$.

2) At the ambient temperature of $311 \mathrm{~K}$, evaporative, vapour compression and vapour absorption recorded a Power Gain Ratio of $9.70 \%, 37.6 \%$ and $51 \%$ respectively.

The above detailed records show that vapour compression and vapour absorption refrigeration precooling techniques will record higher net power output than evaporative precooling because refrigeration precooling techniques cools ambient air beyond the Wet-bulb-temperature (WBT) but vapour absorption refrigeration precooling will record the highest net output power because less parasitic work is consumed unlike in vapour compression precooling system in which more parasitic work is consumed (i.e. power required to drive the refrigeration compressor). This 
research therefore recommends that since evaporative precooling system is favourable in dry and humid areas, it should be used in the northern part of Nigeria provided that the supply of water will not generate a seasonal bottleneck whereas the refrigeration precooling systems can be utilized in the southern region of Nigeria.

\section{References}

[1] Abam FI, Ugot J, Igbong DJ. Performance analysis and component irreversibilities of a 25 MW gas turbine power plant modeled with a spray cooler. American J. of Engineering and Applied Sciences. 2012;5:35-41.

[2] Abam FI, Ugot J, Igbong D.J. Thermodynamic. assessment of grid-based gas turbine power plants in Nigeria. J. Emerging Trends Eng. Applied Sci. 2011; 2:1026-1033.

[3] Cortes CR, Williams DF. Gas turbine inlet air cooling techniques: An overview of current technologies. Power Gen. International, 200; 3Las Vegas Neva, USA.

[4] Shanbghazani M, khalilarra S, Mizael I. Energy analysis of a gas turbine system with evaporative cooling at compressor inlet. Int. J. Exergy. 2008; 5:309325. DOI:10.1504/IJEX.2008.018113.

[5] Dawoud B, Zurigat YH, Bortmany J. Thermodynamic assessment of power requirements and impact of different gas - turbine inlet air cooling techniques at two different locations in Omar. Journal of Applied thermal Engineering. 2005; 25:1579-1598.

[6] Rahim KJ, Majed MA, Galal MZ. Energy, Exergy and thermoeconomics analysis of water chiller cooler for gas turbine intake air precooling. American Journal of thermal Engineering. 2008; 5:3844.

[7] Alhamzy MM, Naijar YSH. Augemntation of gas turbine performance using air coolers. Journal of Applied Thermal Engineering. 2004; 24:425-429.

[8] Mohapatra AK, Prasad L. Parametric analysis of cooled gas turbine cycle with evaporative inlet air precooling. International Journal of Scientific and Engineering Research. 2012; 3:2229-5518.

*Corresponding author.

E-mail address: okaforvictor14@gmail.com 